\title{
Surgical treatment of a floating non-occlusive thrombus in the ascending aorta. Case report.
}

Tratamento cirúrgico de um trombo pedunculado não oclusivo da aorta ascendente: apresentação de caso

Paulo José de Freitas RIBEIRO, Antonio Carlos MENARDI, Walter Vilella de Andrade VICENTE, Paulo Roberto Barbosa EVORA

RBCCV 44205-625

\begin{abstract}
We report the case of a 44-year-old diabetic woman who was a smoker using synthetic progestagen, with previous history of suspected thrombotic cerebral ischemia. She was admitted with clinical evidence of acute myocardial infarction. A coronary angiogram showed normal coronary arteries and distal occlusion of the left circumflex coronary artery. An ascending aorta angiogram and transesophageal echocardiography revealed a free floating mass attached to the aortic wall. The pedunculated thrombotic mass was surgically removed. Histological examination of the resected structure confirmed the macroscopic findings and revealed a recent thrombus. The patient was prescribed oral anticoagulant and released from hospital.
\end{abstract}

Descriptors: Aorta. Aortic disease, thrombosis. Thrombectomy.

\begin{abstract}
Resumo:
Apresenta-se o caso de uma mulher, 44 anos, diabética, fumante crônica, em uso de anticoncepcional, com história prévia de possível isquemia cerebral. Foi atendida no departamento de emergências com infarto agudo do miocárdio. A coronariografia mostrou artérias coronárias normais com oclusão distal da artéria circunflexa. A aortografia e o ecocardiograma transesofágico revelaram uma estrutura pedunculada móvel, flutuante, aderida à parede posterior da aorta ascendente, a qual foi cirurgicamente ressecada. Tinha aspecto macroscópico de trombo recente confirmado pelo exame histológico. A paciente teve alta hospitalar em uso de anticoagulante.
\end{abstract}

Descritores: Aorta, cirurgia. Aorta, patologia. Trombose. Trombectomia.

Hospital do Coração de Ribeirão Preto

CECORP - Centro Especializado do Coração e Pulmão

Support: Fundação Waldemar B. Pessoa

Address for correspondence

Paulo Roberto B. Evora

Rua Rui Barbosa, 367, Ap 15

14015-120 Ribeirão Preto, SP

E-mail: prbevora@keynet.com.br 


\section{INTRODUCTION}

A review of the literature shows that there are few reported cases of embolism or thrombi in non-aneurysmal, effectively normal aorta with no other underlying reasons for thrombus formation in the aorta [1]. Floating masses in the ascending aorta are an uncommon source of systemic embolism, in some cases that do not have an identifiable source [2]. These masses may be thrombi, tumors or infective vegetations.

In most of the reported cases, fatal complications developed, and surgical intervention was undertaken after myocardial infarction, coronary or peripheral occlusion, or after peripheral embolism had already occurred $[3,4]$.

Recently Sodian et al. [5] reported the case of a 55-yearold woman consulted with signs of angina pectoris and dyspnea. Transesophageal echocardiography showed a floating thrombus distal to the right coronary ostium. At operation, a highly mobile thrombus attached to an atherosclerotic plaque distal to the right coronary ostium was found. The atherosclerotic lesion and the pedunculated thrombotic mass were removed without resection of the adjacent aortic wall. In the authors' judgment, a floating mass in the ascending aorta represents an emergency and should be removed before major thromboembolic complications occur. These data motivated the case report of our patient who had antecedents of cerebral ischemia and myocardial infarction.

\section{CASEREPORT}

We report the case of a 44-year-old diabetic woman, who was a smoker on synthetic progestagen, with a previous history of suspected thrombotic cerebral ischemia two years previously. This episode was transitory with complete recuperation of movements in less than 24 hours.

She was admitted to the emergency department for an acute anterior myocardial infarction. Coronary angiogram showed normal coronary arteries and distal occlusion of the left circumflex coronary artery with well-preserved left ventricle function. Ascending aorta angiogram revealed a free floating mass attached to the aortic wall without evidence of aortic dissection. A transthoracic echocardiogram did not show intracardiac thrombi. A transesophageal echocardiography confirmed the presence of a pedunculated mobile mass attached to the posterior aortic wall not too close to the aortic valve aortic valve (Figure 1). Also, a magnetic resonance confirmed the aortic mass, but the transesophageal echocardiography image was of better quality.
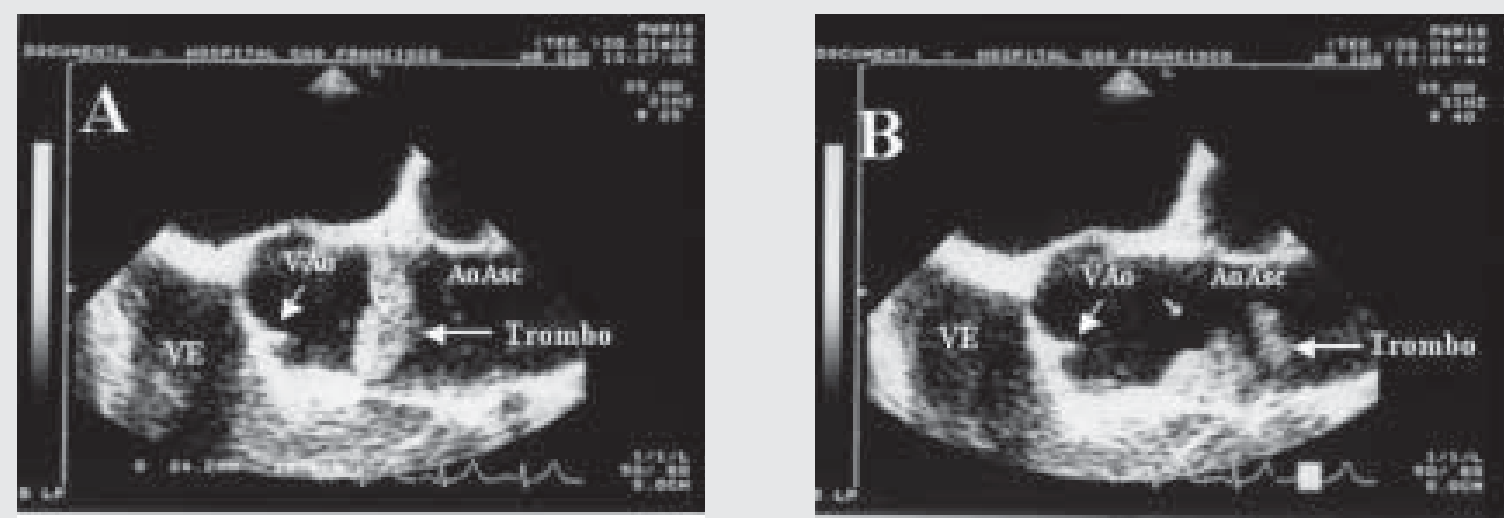

Fig. 1 - Long-axis echocardiograms showing pedunculated thrombus (arrow) in ascending aorta with aortic valve in closed position. $(L V=$ left ventricle; $A o V=$ aortic valve; $A s c A o=$ ascending aorta $)$ 
The patient underwent urgent surgery. Intra-operatively a floating mass, similar to an old thrombus, was localized in the posterior wall of ascending aorta (Figure 2). On
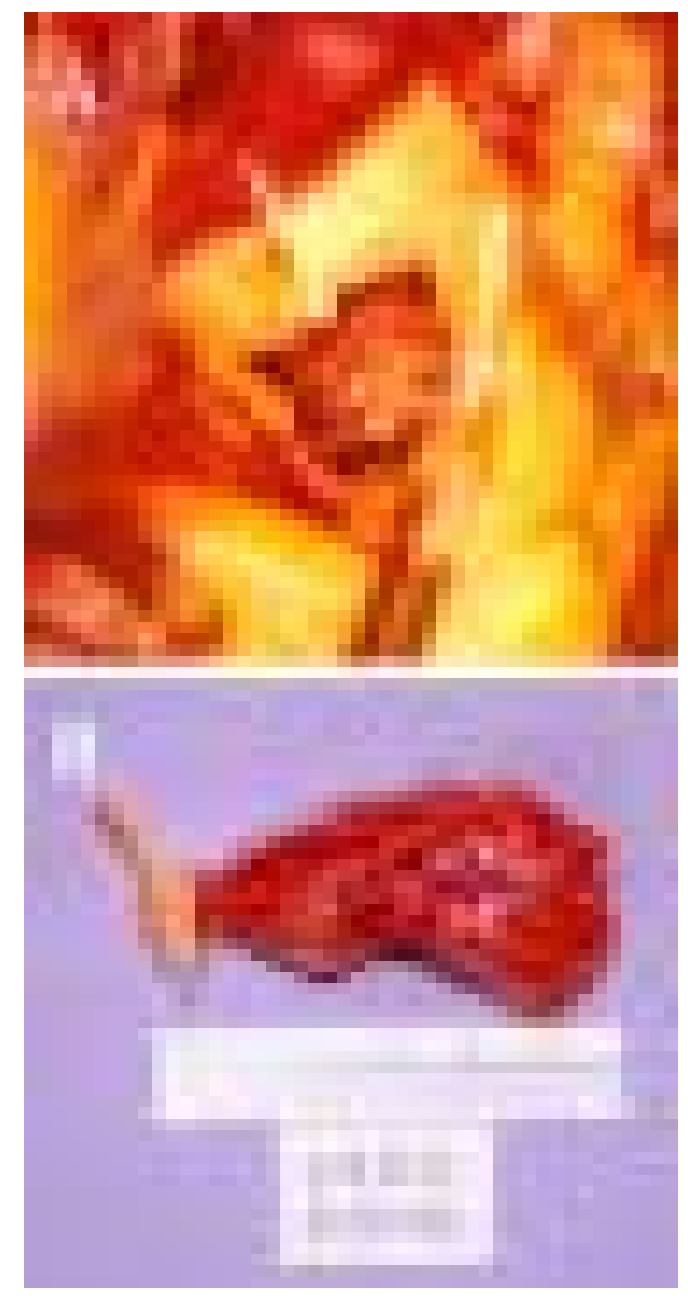

Fig. 2 - A) The thrombus is attached to the posterior aortic wall, B) Macroscopic view of the resected thrombus, showing part of the aortic resected wall $(27 \times 12 \times 10 \mathrm{~mm})$.

macroscopic examination the aortic wall and leaflets were normal. The pedunculated thrombotic mass was removed with resection of the adjacent aortic wall, which was sutured directly. The surgery and the postoperative period were uneventful, and the patient was dismissed on the fifth day under oral anticoagulation.

Histological examination of the resected structure confirmed the macroscopic findings and revealed a recent thrombus with evident organization process measuring 27 $\mathrm{mm} \times 12 \mathrm{~mm}$ x $10 \mathrm{~mm}$. The aortic segment presented hyaline material with suggestive microscopic signs of atherosclerosis. There were no signs of infection.

\section{COMMENTS}

Floating structures in the ascending aorta are rarely reported. When they occur, severe central and peripheral thromboembolic complications can result [3]. Other investigators have reported systemic thromboembolic complications and even coronary occlusion leading to infarction and ultimately death [6]. In our case it was not possible to know if the previous cerebral thromboembolic episode had been caused by the resected mass. Maybe it was a consequence of microscopic emboli formed and released from the structurally and functionally damaged endothelium of the aortic wall associated to diabetes.

When similar thrombi to the one in our patient have occurred, they have been associated with major complications such as severe myocardial infarction and peripheral embolism [4]. Some authors hypothesized that atherosclerotic plaques and a hypercoagulable condition might cause a thrombus in the ascending aorta $[7,8]$ However, the exact mechanisms of giant thrombi in a highflow environment such as the ascending aorta are not fully known. In our patient no sophisticated coagulation tests were performed, but the routine preoperative coagulogram was normal.

Some investigators reported successful thrombolytic treatment of an aortic arch thrombus [9]. Anticoagulant therapy was reported in a 50-year-old woman admitted because of renal infarction caused by a floating thrombus, detected by transoesophageal echocardiography and magnetic resonance imaging, in the descending aorta. She was a poor surgical candidate due to obstructive lung disease and obesity. Under intravenous heparinization with prothrombin time test values between 80 and 100 seconds, the thrombus resolved after 10 weeks and no recurrence occurred over the next 30 months [10]. Even considering the possibilities with thrombolytic and/or anticoagulant therapy we have to consider the high risk of thromboembolism and therefore the decision to remove the mass surgically may be safer. The surgical treatment under normothermic cardiopulmonary bypass was our therapeutic decision.

Whereas surgical resection of an atheromatous lesion has been reported to be successful in patients with plaquerelated thrombi in the aortic arch, this resection may increase surgical risk because the plaque may be located very close to the coronary ostium. Also, excision of a small button of the aortic wall surrounding the pedunculated thrombus and a local patch graft close to the coronary ostium may even increase the risk of perioperative thromboembolic and ischemic complications. The decision whether or not to resect the atheromatous aortic wall should be made on an individual basis depending on the localization, morphology, 
and size of the thrombus and the attached aortic wall. We resected the aortic wall, which was directly sutured without a patch graft.

Finally, it must be emphasized that transesophageal echocardiography provided almost all the information necessary for the surgical treatment of the floating mass, morphology, mobility, dimensions, and the exact localization. Therefore, the evaluation of patients with unexplained disorders of the ascending or descending aorta or the presence of myocardial ischemia with normal coronary arteries should include investigation with transesophageal echocardiography [5].

\section{BIBLIOGRAPHIC REFERENCES}

1. Kolvekar SK, Chaubey S, Firmin R. Floating thrombus in the aorta. Ann Thorac Surg 2001; 72: 925-7.

2. Kalangos A, Baldovinos A, Vuille C, Montessuit M, Faidutti B. Floating thrombus in the ascending aorta: a rare cause of peripheral emboli. J Vasc Surg 1997; 26: 150-4.
3. Farah MG, Hawawini $\mathrm{H}$. Thrombus of the ascending aorta as a source of cerebral embolism. Chest 1993; 104: 1604-5.

4. Bruno P, Massetti M, Babatasi G, Khayat A. Catastrophic consequences of a free floating thrombus in ascending aorta. Eur J Cardiothorac Surg 2001; 19: 99-101.

5. Sodian R, Bauer M, Weng YG, Siniawski H, Koster A, Hetzer $\mathrm{R}$ - Floating nonocclusive thrombus in the ascending aorta. Ann Thorac Surg 2002; 74: 588-90.

6. Dunkman WB, Johnson GR, Carson PE, Bhat G, Farrell L, Cohn JN. Incidence of thromboembolic events in congestive heart failure. The V-HeFT VA Cooperative Studies Group. Circulation 1993; 87(6 Suppl): VI 94-101.

7. Fuster V, Badimon JJ, Chesebro JH. Atherothrombosis: mechanisms and clinical therapeutic approaches. Vasc Med 1998; 3: 231-9.

8. Amarenco P, Cohen A, Tzourio C, Bertrand B, Hommel M, Besson $\mathrm{G}$ et al - Atherosclerotic disease of the aortic arch and the risk of ischemic stroke. N Engl J Med 1994; 331: 1474-9.

9. Hausmann D, Gulba D, Bargheer K, Niedermeyer J, Comess KA, Daniel WG. Successful thrombolysis of an aortic-arch thrombus in a patient after mesenteric embolism. N Engl J Med 1992; 327: 500-1.

10. Stollberger C, Kopsa W, Finsterer J. Resolution of an aortic thrombus under anticoagulant therapy. Eur J Cardiothorac Surg 2001; 20: 880-2. 